\title{
Persons with physical disabilities' experiences of rehabilitation services at Community Health Centres in Cape Town.
}

\begin{abstract}
Background: Rehabilitation is of fundamental importance for the persons with disability to achieve functional independence and have an improved quality of life. To enhance the effectiveness of rehabilitation, it is important to seek clients' perspectives of the rehabilitation services and to incorporate these perspectives into the planning and delivery of rehabilitation services. The aim of this study was to explore the persons with physical disabilities' experiences of the rehabilitation services they received at Community Health Centres (CHCs).
\end{abstract}

Methods: In-depth qualitative interviews were used to collect data. Ten persons with physical disabilities, who had received rehabilitation services at CHCs participated in the in-depth interviews. The interviews were tape-recorded and transcribed verbatim. Thematic analysis was used to analyse the data.

Results: The clients experienced problems with accessing transport and obtaining information from the service providers. Experiences regarding clients' involvement in the rehabilitation were varied. All the clients reported positive experiences regarding their interaction with service providers and family involvement.

Conclusion: The experiences of the participants who accessed CHCs for rehabilitation were positive and negative. The service providers should therefore address the aspects of rehabilitation that were negatively experienced.

\section{KEY WORDS: EXPERIENCES, REHABILITATION SERVICES, PHYSICAL DISABILITY.}

\section{Introduction}

Living with a disability can interfere with a person's ability to participate actively in economic and social life (Phillips \& Noumbissi, 2004). This is exacerbated in contexts where rehabilitation services are unavailable or inadequate. Rehabilitation is therefore of fundamental importance for the persons with disability to achieve functional independence and have an improved quality of life. The goal of rehabilitation is to enable individuals to return to their communities with the highest possible level of functional independence and the best possible quality of life, while at the same time reducing, as far as possible, the burden of care (Department of Health, Western Cape,

\section{Correspondence to:}

C. K. Kahonde

University of the Western Cape

Private Bag X17

Bellville

7535

E-mail:callistakahonde@yahoo.com
2007). To enhance the effectiveness of rehabilitation, it is important to seek clients' perspectives of the rehabilitation services and to incorporate these perspectives in the planning and delivery of rehabilitation services. The feedback informs the service providers about the service users' perception of the quality of the service provided. This approach is based on the social model of disability (Wressle, 2002).

The social model of disability enhances the control and status of the service user as opposed to control and status of the service provider, emphasising a shift in the role of both service users and their relatives in the rehabilitation process (Wressle, 2002). It is recommended under the social model of disability that a shift occurs from emphasis on the service providers' views to seeking service users' views on rehabilitation services. Knowledge of service users' experiences regarding rehabilitation services has become vital, especially in the rehabilitation of persons with physical disabilities, as services are usually long term for this group of people. Furthermore, the service users' experiences are a useful way of monitoring the services for quality assurance, rather than only basing it on the service providers' reports $(\mathrm{DOH}$, 2000). Despite emphasis on the shift to more involvement of the clients, the control of rehabilitation services is still mainly in the hands of the service providers. Patients are not consistently involved in treatment planning and evaluation (Payton \& Nelson, 1996).

A number of common factors are reported with regard to variables associated with service users' experiences across studies in health care and rehabilitation (Crisp, 2000, Garrat et al, 2006, Lund, 2004, Morris et al, 2007). These include service user participation and involvement, family and caregiver involvement, information provision, interaction with service providers, respect for service user, emotional support, accessibility of the services, physical comfort and service providers' expertise. For instance, in the study 
based on stroke service in the United Kingdom, Morris et al (2007), reported that individual information about the stroke and treatment and what to expect after discharge were highlighted as problem areas and lack of information engendered anxiety among the clients and their families. Crisp (2000) reported that in Australia, disabled people were concerned about lack of quality in their relationships with health and rehabilitation professionals.

Historically in South Africa, rehabilitation services within the public sector were predominantly located within secondary/tertiary institutions. These services focused on individual therapy utilising the medical model approach (Office of the Deputy President, 1997). Since the last decade, there has been a shift from delivering health services at tertiary level facilities to primary health care services (Department of Health, Western Cape, 2003). Community Health Centres (CHCs) were designed to offer primary health care services within communities. These centres, which are the setting for the present study, should offer preventative, promotive, curative and rehabilitative services (ANC, 1994). The rehabilitation services at these centres are offered by physiotherapists and occupational therapists (Chief Physiotherapist, CMHD, personal communication, September 2008). The rehabilitation services provided include individual and group treatment sessions, support groups, home and work visits and training of carers and community members (Rhoda, 2002; de la Cornellere, 2006).

Although rehabilitation services have been offered at CHCs for more than a decade, there is minimal information gathered and documentation regarding the service users' experiences of these services. Hence, the aim of this study was to explore the persons with physical disabilities' experiences of rehabilitation services received at $\mathrm{CHCs}$ in Cape Town Metro Health District.

\section{Methods}

\section{Design}

The study used both qualitative and quantitative methods. The qualita- tive study design and findings will be reported in this paper and the quantitative part of the study is reported elsewhere. The qualitative study used in-depth interviews to explore the experiences of persons with physical disabilities regarding rehabilitation services at $\mathrm{CHCs}$ in Cape Town Metro Health District.

\section{Sample}

The sample consisted of ten individuals purposefully selected from the persons with physical disabilities who had received rehabilitation services at the CHCs for a period of three months or more. The persons receiving rehabilitation at the centres include those with conditions such as stroke, amputations, head injuries and spinal cord injuries (Chief Physiotherapist, CMHD, personal communication, September 2008). The characteristics considered for the selection of the participants were age, gender, duration of rehabilitation and diagnosis.

\section{Instrumentation}

An interview guide which consisted of open-ended, non-directive questions was used to explore the participants' experiences regarding accessibility of the services, service user's interaction with service providers, participation and involvement of the service user, family and caregiver involvement in the rehabilitation process and information regarding disability and support services for persons with disability. Probes were used to obtain in-depth descriptions of the participants' experiences with the rehabilitation services received. The areas which were explored were identified from the literature (Crisp, 2000; Lund, 2004; Garrat et al. 2006)

To ensure trustworthiness (Lincoln and Guba, 1985) in this study, the interview guide was developed after the researcher conducted a literature review (Payton et al. 1998; Morris et al. 2007) to find out what most clients with physical disabilities have reported as their experiences of health care and rehabilitation services they received. Once the interview guide was developed, two individuals with expertise in the field of disability and rehabilitation, who also have experience of working with persons with physical disability at $\mathrm{CHCs}$, were requested to review the guide to ensure that all the relevant concepts relating to service users' experiences with rehabilitation services were explored.

\section{Procedure}

Selected participants were contacted telephonically to explain the purpose of the study and were requested to participate in the study. An appointment to conduct the interviews was made with those who agreed to participate in the study during telephone conversations. The interviews occurred at a time and place that was convenient for the participants. Eight of the interviews were conducted at the $\mathrm{CHCs}$ and the remaining two were conducted at the participants' workplaces. Participants who travelled to the CHCs were provided with money for transport. Written informed consent was obtained before the interviews took place. The interviews were conducted in quiet rooms that were private, comfortable, and non-threatening to the participants or within a cubicle in the physiotherapy department. The participants were given an option of the language in which the interviews could be conducted. Four of the interviews were conducted in isiXhosa by a physiotherapist knowledgeable in the field of rehabilitation who was fluent in the language. The remaining six were conducted in English by the primary author. All the interviews were tape-recorded after consent to do so was gained from the participants.

\section{Data analysis}

Analysis of data began with verbatim transcriptions of all the interviews. A person who was fluent with the specific language, that is, English or isiXhosa transcribed the interviews. The transcripts were then compared to the voice recordings to verify accuracy. The isiXhosa transcripts were translated into English after the recordings were verified. Data analysis was done using the following predetermined themes: accessibility, involvement of participants in their rehabilitation, involvement of family and caregivers in the rehabilitation process, interaction of service providers with the participants and information given by the service 
providers. Each theme was coded into categories of related information and corresponding verbatim quotations were put under different categories to support each theme. Two individuals with expertise in the field of disability and rehabilitation did peer reviewing of the transcripts to verify the identified themes and categories.

\section{Ethical considerations}

The study obtained ethical approval from the University of the Western Cape's Senate Research Grants and Study Leave Committee and the Director of the Cape Metro District Health Services. Informed consent was obtained from each participant and confidentiality was maintained by keeping the transcripts and the tape recorder in locked cardboards. Permission was also sought from each participant to record the interviews. Participants were informed that they could withdraw anytime during the interviews without fear of losing any of their entitlements. Confidentiality was maintained by using pseudonyms throughout the study (C1-C10), instead of participants' actual names.

\section{Results and Discussion}

\section{Participants' characteristics}

The study sample consisted of four females and six males. The mean age of the participants was 51 years $(\mathrm{SD}=8.9)$. The participants' characteristics were as shown in Table 1.

\section{Accessibility of the services}

The main issues that arose under this theme were transport and physical access. The participants expressed the challenges experienced while accessing the centres to receive rehabilitation. The public transport system was not accessible to people with disabilities. In previous findings, persons with disabilities have indicated that they experienced problems with stopping the buses and taxis as well as overcrowding of these vehicles (Office of the Premier Western Cape, 2002). The participants in the present study also reported that they had similar problems with accessing public transport as is highlighted in the following quotations:

Table 1: Participants' characteristics

\begin{tabular}{|l|l|l|l|l|}
\hline Name & Gender & Age (yrs) & Diagnosis & $\begin{array}{l}\text { Time since } \\
\text { acquiring } \\
\text { disability (yrs) }\end{array}$ \\
\hline C1 & female & 50 & stroke & 0.25 \\
\hline C2 & male & 33 & head injury & 4 \\
\hline C3 & male & 48 & $\begin{array}{l}\text { spinal cord } \\
\text { injury } \\
\text { (paraplegia) }\end{array}$ & 18 \\
\hline C4 & female & 65 & stroke & 0,25 \\
\hline C5 & female & 63 & stroke & 0.5 \\
\hline C6 & female & 47 & $\begin{array}{l}\text { below knee } \\
\text { amputation }\end{array}$ & 1 \\
\hline C7 & male & 54 & head injury & 2 \\
\hline C8 & male & 53 & $\begin{array}{l}\text { spinal cord } \\
\text { injury } \\
\text { (paraplegia) }\end{array}$ & 3 \\
\hline C9 & male & 50 & $\begin{array}{l}\text { head injury } \\
\text { injury } \\
\text { (paraplegia) }\end{array}$ & 2 \\
\hline & 50 & 59 cord & 11 \\
\hline
\end{tabular}

"The taxis are not the same, there are those who stop for me and some others don 't..." (C8, paraplegia).

"It's not easy for me you see, sometimes those taxis don't stop for me, I have to find my own transport to come to the day hospital..." (C3, paraplegia).

The problems faced when using public transport meant that the participants had to hire transport from neighbours and had to pay a fee, which obviously strained them financially as is expressed below by a person with a stroke.

\section{"My son brings me. If he can't I have to ask someone to take me to the hospital then we must pay. We pay R50, or whatever they charge, paying is the problem you see..." (C4, stroke).}

The lack of appropriate transport results in poor attendance of follow-up treatments sessions as was reported by two studies conducted in Cape Town.
Whitelaw et al (1994) found that rehabilitation of stroke clients at a tertiary hospital in Cape Town was unsatisfactory because of poor attendance due to transport problems. De la Cornillere, (2007) also reported that at one of the CHCs in Cape Town transport was the major problem interfering with attendance of rehabilitation sessions.

Some of the participants did not utilise transport as they walked to the centres. Walking was also difficult as they got tired as is expressed by the following participant:

"I am so busy experiencing like now I am experiencing problems walking. I get tired man, but I still walk... " (C2, head injury).

Community ambulation has been reported as a major challenge for people who have impairments as a result of a stroke (Lord et al., 2008). It is therefore important that the public transport system is "flexible and accessible" as recommended by the Integrated National 
Disability Strategy (Office of Deputy President, 1997:32). Accessible public transport will also help to enhance the livelihood of persons with disability by enabling them to access other services other than CHCs, like schools, shops, workplaces and recreational places.

Inaccessible physical environments have been reported in the literature to hinder service users in their receipt of adequate rehabilitation services (Rimmer et al., 2000, Levins et al., 2004). However, in the present study, physical access was reported to be generally good by the participants. One of them related;

"Yeah at the gate there is no problem. Even moving around the clinic with my wheelchair, it is alright. It's ok I just pass through the doors and everywhere." (C3, paraplegia).

The positive experiences in the present study could be due to the fact that the rehabilitation departments at the $\mathrm{CHCs}$ were built bearing in mind that they would service this group of people and therefore accessibility issues were taken into consideration. On the other hand, in the literature participants report on accessibility of a variety of places for example, private clinics and doctors' surgeries.

The only negative experience regarding physical accessibility was about the state of the toilets. One lady, with stroke who was using a wheelchair raised a strong complaint about the accessibility of the toilets.

"I definitely think they should do something with the toilets. Sometimes I went to the toilets, the people struggle a lot. I think they can put like rails in the toilets for the disabled people so we can at least balance on that while we are moving. Sometimes we have to wait, there are two toilets and we have to wait. We need something to lean on. The space is also small in that toilet, it's not nice..." (C4, stroke).

\section{Interaction of service providers with participants}

The participants in the present study experienced the attitudes of the service providers positively. When asked about their interaction with service providers, they mentioned that the service providers respected them, communicated well with them and supported them emotionally. These results confirm the findings by Crisp (2000) that service provider attitudes were a major issue that clients talked about when reporting their experiences of rehabilitation and health care. All the participants gave positive remarks about the way the service providers interacted with them and they kept on referring to these attitudes even when the interviewer asked about other aspects of rehabilitation. These results are however contrary to the findings in other studies (Crisp, 2000, Swain \& French, 2001), which suggest that disabled people can experience their relationships with service providers as ineffectual, dehumanising and abusive. However, these two studies looked at different service providers including rehabilitation therapists, nurses and doctors. The positive attitudes of the physiotherapists and occupational therapists in the present study might be largely due to their experience of working with persons with physical disabilities as Budisch (2004) suggests that the more contact one has with persons with disability, the more familiar they become with disability and hence the more positive their attitudes become. Participants expressed the following with regards to their interaction with service providers:

"They treat me well and they show respect. The physio people are caring and they understand what kind of person you are regarding disability...", (C6, below knee amputation).

"It is the second time seeing the OT but I always come to see the physio but they both treat me well..." (C1, stroke).

"Ah I must say the people at the physio and at the clinic have been nice towards me..." (C2, head injury).

Although lack of care for emotional needs of service users was found to be common in studies reporting on rehabilitation experiences of persons with disability (Biggs, 2008, Hammel, 2007), the participants in the present study reported that the service providers took care of their emotional needs. Some of them said the following:

"Yes they talk to me, what can I say? I mean they encourage me when I feel down..." (C5, stroke).

"When I just had the stroke I came here and she said to me when you feel like crying cry, don't keep it in because it will make you more frustrated..." (Cl, stroke).

The fact that the interviews were conducted within the premises where the clients were receiving the rehabilitation services could have been a major factor contributing to the participants giving positive responses regarding the service provider attitudes. Future research is recommended in which the clients will be interviewed in a neutral environment where they do not fear being heard by the service providers.

\section{Client participation and involvement in rehabilitation}

The National Rehabilitation Policy in South Africa emphasises the need for direct involvement of persons with disabilities and their families in decisionmaking because they have first-hand experience of the impact of disability on their lives (DOH, 2000). Similar to findings in other studies (Payton et al., 1998, Lund, 2004), the participants in the present study had mixed feelings regarding their involvement in the rehabilitation sessions. Although they reported that the service providers involved them in their rehabilitation, some felt that the service providers implemented their treatment without providing any explanation to the client about the treatment procedures. The following statements relate to participation and involvement:

"Yes the physio asked me since the first time I was here every time that I came I must tell her what I want to do and like now I told her I want to sweep and she gave me this thing to use with the broom..." (Cl, stroke). 
"No. It was her who asked me last week what was the thing that I would like to do most and she told me to write it down..."(C2, head injury).

Despite the positive responses given above concerning service user involvement, it would not be easy from these results to discern their level of involvement in decision making since some of them made it clear that they would accept what the therapists offered because they believed that the therapists knew everything. For instance, one lady said,

"No, you people have got the qualification, you people have got the knowledge about these things and I haven't got to ask. If I ask, I don't know what to ask because I don't know anything about the sickness and the hospital but you people know. I just do what they say." (C4, stroke).

These findings were related to those reported by Wressle (2002), which showed that some elderly service users were not confident enough to ask questions and were not used to making demands on care, relying instead on the knowledge of the professionals. It is however, interesting to note that another study (Payton et al, 1998) discovered that although some service users do not appear to want to be involved, there is evidence that those who get involved are more satisfied with their health care experience and have better therapeutic outcomes.

Some of those who thought they were not being involved in the rehabilitation sessions said the following:

"They just tell me what to do..." (C9, head injury).

"Sometimes they just do their own thing and I just tell them sorry but I don't know what you are doing now..." (C2, head injury).

Although South African policy documents advocate for service users' active participation and involvement in rehabilitation (DOH, 2000) the results of the present study revealed that the service users are not aware of their right to participate in their rehabilitation. It is apparent from these results that in order for persons with disabilities to be involved in the rehabilitation programmes they need to be enlightened about their right to be involved and the importance of doing so. Empowerment of persons with physical disabilities through educational programmes is indicated to help them to feel free to express themselves during rehabilitation and not just accept what the therapist wants. This is especially important in cases where the former are not satisfied. This notion is supported by Lui and Mackenzie (1999) who in their study to investigate needs of stroke clients concluded that gaining knowledge helps the service users as a means of controlling their feelings of powerlessness.

\section{Family/caregiver involvement in reha- bilitation}

Only four of the participants had gone for rehabilitation to the CHCs with a caregiver or family member. They generally gave positive responses regarding family and caregiver involvement in rehabilitation especially as far as how to care for the participant at home was concerned. It was unfortunate though, that the persons with physical disabilities were the informants regarding family involvement and not the family members themselves. In previous studies, which looked at family involvement, feelings of stress and frustration have been reported by the family members due to lack of information regarding home programmes and transition from hospital to community care (Payton et al, 1998, Hare et al, 2006). Participants expressed the following:

"Yes they explain to them (family), because even at home I must exercise especially when I am going to sleep. I must put some cushion under this leg and continue doing what we did while I was here..." (C6, below knee amputation).

"Yes they do, they even show them how they can help at home to do types of exercises. She would show you if you come with someone, they say "Come and see so that you can help at home, while she waits for the next appointment this is how it must be done and this is how you do it..." (C4, stroke).

\section{Provision of information}

The participants in the present study reported that they received information regarding the nature of their disabilities. Some of them said the following:

"Yeah, they told me I won't to be able to walk again due to the spinal cord injury, that's all they told me, the injury was very low at L1 level..." (C3, paraplegia).

\section{"Yes they told me. I know. I know what a stroke entails..." (C5, stroke).}

They were however not provided with sufficient information regarding support services. This is consistent with previous findings (Schneider et al, 1999), in which rehabilitation service users in South Africa expressed their need for information regarding support groups, disability grants, vocational training and other support services available for them. They said the following:

"No I was not told anything about my rights or support groups or anything. I don't know..." (C7, head injury).

"No, I don't know about those things but I am too shy to ask them..." (C1, stroke).

When asked whether they would ask the service providers for information regarding their disabilities, it was apparent that most of the participants did not intend following up on gaining more knowledge about their disabilities. Four of the participants said they would not ask the therapists questions. As mentioned before, some of them believed that the therapists knew everything so they just had to follow what they were told without questioning.

Surprisingly, one of the participants who had said she was shy to ask questions asked the researcher about the disability grant, something that they should have asked the service providers. She said: 
"Yeah, now tell me something. I actually want to ask. If I want to ask someone if I could get a disability grant, would I...?" (C1, stroke).

This could be a sign that despite the reported positive experiences regarding interaction with service providers, the service users were not open enough to share their concerns with the latter. This indicates the need to encourage client involvement in rehabilitation so as to enhance partnership between service providers and persons with disabilities, which might improve the latter's openness to discuss their concerns with service providers. This will in turn improve empowerment of service users and encourage them to take ownership of the rehabilitation process as encouraged by the NRP (DOH, 2000) in South Africa.

\section{Conclusion}

The study revealed that the service users experienced problems with accessing the rehabilitation facilities, getting information regarding support services and some were not given enough opportunity to participate in the rehabilitation process. All these problems could be a hindrance for the clients receiving adequate rehabilitation. It is therefore recommended that the department of transport ensures that the public transport services are accessible to persons with disabilities. There is also need to educate public transport operators about disability so as to remove the discriminatory behaviour towards persons with disabilities. The rehabilitation service providers should provide the persons with disabilities with information regarding support services and also facilitate their involvement in the rehabilitation process.

\section{References}

African National Congress (ANC). 1994. A National Health Plan for South Africa. ANC, Johannesburg.

Biggs D 2008 Health Risk Behaviours of Stroke Patients in the Western Cape, South Africa. South African Journal of Physiotherapy 64(1): 38-42.

Budisch K 2004 Correlates of College Students' Attitudes Towards Disabilities. Journal of Undergraduate Research 7: 1-5.

Crisp R 2000 A Qualitative Study of the Perceptions of Individuals with Disabilities Concerning Health and Rehabilitation Professionals. Disability and Society 15(2):355-367.

de la Cornillere W-L 2007 Participants' experiences of the Bishop Lavis Rehabilitation Centre stroke group. Unpublished Master's Thesis. Centre for Rehabilitation Studies. University of Stellenbosch. South Africa.

Department of Health 2000 Rehabilitation for All. National Rehabilitation Policy. Pretoria: South African Government Printers.

Department of Health Western Cape 2003 Healthcare 2010: Health Western Cape's plan for ensuring equal access to quality health care. Department of Health, Western Cape: Cape Town.

Garrat A, Bjorngaard JH, Dahle KA, Bjertnes OA, Saunes IS, Ruud T 2006. The Psychiatric Outpatient Experiences Questionnaire (POPEQ): Data quality, reliability and validity in patients attending 90 Norwegian clinics. Nordic Journal of Psychiatry 60: 89-96.

Hammel KW 2007 Experiences of rehabilitation following spinal cord injury: a meta-synthesis of qualitative findings. Spinal Cord 45(4): 260-274.

Hare R, Rogers H, Lester H, McManus RJ, and Mant J 2006. What do stroke patients and their carers want from community services? Family Practice 23(1): 131-136.

Levins SM, Redenbach DM, Dyck I 2004 Individual and Societal Influences on Participation in Physical Activity Following Spinal Cord Injury: A Qualitative Study. Physical Therapy 84(6): 496-509.

Lincoln YS, Guba EG 1985. Naturalistic Inquiry. Sage publications, Newbury Park, California.

Lord S, McPherson KM, McNaughton HK, Rochester L, Weatherall M 2008 How feasible is the attainment of community ambulation after stroke? A pilot randomised controlled trial to evaluate community based physiotherapy in sub-acute stroke. Clinical Rehabilitation 22(3): 215-225.

Lui MHL, Mackenzie AE 1999 Chinese elderly patients' perceptions of their rehabilitation needs following a stroke. Journal of Advanced Nursing 30(2): 391-400.

Lund ML 2004 Living with physical disability. Experiences of the rehabilitation process, occupations and participation in everyday life. (Doctoral dissertation). Umea, Sweden: Umea University, Department of Community Medicine and Rehabilitation, Occupational Therapy.

Morris R, Payne O, Lambert A 2007 Patient, carer and staff experiences of hospital based stroke service. International Journal for Quality Health Care 19(2): 105-112.

Ministry in the Office of the Deputy President 1997 Integrated National Disability Strategy White Paper, Government of South Africa, Pretoria, Government Printers.

Office of the Premier. Western Cape Province (2002) Integrated Provincial Disability Strategy.

Payton OD, Nelson CE 1996 A preliminary study of patients' perceptions of certain aspects of their physical therapy experience. Physiotherapy Theory and Practice 12(1): 27-38.

Payton OD, Nelson CE, Hobb MS 1998 Physical therapy patients' perceptions of their relationships with health care professionals. Physiotherapy Theory and Practice 14(4): 211-221.

Phillips H, Noumbissi A 2004 Disability in South Africa. African Population Studies/ Etude de la Population Africaine 19(2): 115-138.

Provincial Government of the Western Cape Health Department 2007 Comprehensive Service Plan for the Implementation of Health Care 2010.

Rimmer JH, Rubin SS, Braddock D 2000 Barriers to exercise in African American Women with Physical Disabilities. Archives of Medicine and Rehabilitation 81(2): 182-188.

Rhoda A 2002 A profile of stroke patients treated at the Bishop Lavis Rehabilitation Centre: 1995-1999. Stellenbosch University, Cape Town.

Scheneider M, Claassens M, Kimmie Z, Morgan R, Naicker S, Roberts A, McLaren P 1999 We also count! The Extent of Moderate and Severe reported Disability and the Nature of the Disability Experience in South Africa. Household Survey for the Department of Health. Community Agency for Social Enquiry.

Swain J, French S 2001 The relationship between disabled people and health and welfare professionals, in Albrecht, GL, Seelman KD, Bury M (eds) Handbook of Disability Studies Thousand Oaks: Sage.

Whitelaw DA, Meyer CJ, Bawa S, Jennings K 1994 Post-discharge follow-up of stroke patients at Groote Schuur Hospital-a prospective study. South African Medical Journal 84(11): 11-13.

Wressle E 2002 Client participation in the rehabilitation process. Doctoral dissertation No. 722 . Division of Occupational Therapy, Department of Neuroscience and Locomotion, Faculty of Health Sciences, Linköpings Universitet, SE-581 85 Linköping, Sweden. 